\title{
Sound Level Monitoring at Live Events, Part 2-Regulations, Practices, and Preferences
}

\author{
JOHANNES MULDER, ${ }^{1}$ ADAM J. HILL, ${ }^{2}$ AES Member, JON BURTON, ${ }^{2}$ AES Member, \\ (Jos.Mulder@anu.edu.au) \\ (a.hill@derby.ac.uk) \\ (j.burton2@derby.ac.uk) \\ MARCEL KOK, ${ }^{3}$ AES Student Member AND MICHAEL LAWRENCE ${ }^{4}$ \\ (mail@dbcontrol.nl) \\ (michael@rationalacoustics.com) \\ ${ }^{1}$ College of Arts and Social Sciences, The Australian National University, Canberra, Australia \\ ${ }^{2}$ College of Science and Engineering, University of Derby, Derby, DE22 1GB, UK \\ ${ }^{3}$ dBcontrol, Zwaag, Netherlands \\ ${ }^{4}$ Rational Acoustics, Woodstock, CT, USA
}

\begin{abstract}
This paper considers existing regulations, practices, and preferences regarding the measurement, monitoring, and management of sound levels at live music events. It brings together a brief overview of current regulations with the outcomes of a recent international survey of live sound engineers and evaluation of three datasets of sound measurement at live music events. The paper reveals the benefit of a 15-min time frame for the definition of equivalent continuous sound level limits in comparison to longer or shorter time frames. The paper also reveals support from the live sound engineering community for the application of sound level limits and development of a global certification system for live sound engineers.
\end{abstract}

\section{O INTRODUCTION}

Before the COVID-19 pandemic halted entertainment events across the globe, including music concerts, the live music industry united people across a wide range of venues: bars, clubs, festivals, arenas, and stadia. Not only is live music a great social good, it is also a multibillion dollar industry on a plethora of different local, national, and international scales. The issue of nuisance noise for people living in the proximity of venues is well documented, and in many places regulations and practices to address this are well established.

Audience exposure to high sound levels and the ensuing risks of hearing damage have been common knowledge and are well documented. However regulations and guidelines addressing this issue of audience exposure are relatively rare and emerging in only a handful of countries.

This paper is part of a series of three and presents and analyzes three different varieties of data. First, an overview of current regulations that specifically target audience exposure. Second, a survey of live sound engineers (LSEs) on the topic of sound level exposure and regulation. And third, a quantitative analysis of sound pressure level (SPL) data collected at a great range of different events. The aim of this paper is to disseminate and critically review the evidence that is currently available for the evaluation of existing provisions and development of new regulations and guidelines.

At the time of writing, the World Health Organization (WHO) Make Listening Safe (MLS) ${ }^{1}$ initiative is preparing a global standard for control of sound exposure in recreational venues. The authors are part of the Technical Working Group that supports the realization, and this trio of papers is intended to inform the development of the standard.

\section{EXISTING REGULATIONS}

Specific regulations and licensing frameworks addressing environmental noise (i.e., nuisance for neighbors) and live events have been around for several decades and vary greatly between countries or smaller jurisdictions (e.g., states, individual cities). The Audio Engineering Society Technical Committee on Acoustics and Sound Reinforcement recently created a technical document that provides

${ }^{1}$ https://www.who.int/news-room/events/detail/2020/02/17/ default-calendar/consultation-on-make-listening-safe-2020. 
Table 1. European examples of $\mathrm{L}_{\text {Aeq }}$ limits regulated to reduce audience exposure to high sound levels. $\mathrm{A}$ and $\mathrm{C}$ indicate the weighting; F indicates a fast integration time (125 ms).

\begin{tabular}{llll}
\hline Country & LAeq $(\mathrm{dB})$ & Time $(\mathrm{min})$ & Additional \\
\hline Belgium & $100 / 102$ & $60 / 15$ & \\
France & 102 & 15 & $\mathrm{~L}_{\mathrm{Ceq}, 15 \min }=118 \mathrm{dBC}$ \\
Germany $^{2}$ & 99 & 30 & $\mathrm{~L}_{\mathrm{Cpeak}}<135 \mathrm{dBC}$ \\
Netherlands & 103 & 15 & $\mathrm{~L}_{\mathrm{Cpeak}}<140 \mathrm{dBC}$ \\
Switzerland & 100 & 60 & $\mathrm{~L}_{\mathrm{AF}}<125 \mathrm{dBA}$ \\
\hline
\end{tabular}

a detailed overview [1]. Currently there is no standard approach to sound level rules and regulations. Discrepancies exist in the metrics used to specify maxima but also in how and where to measure, how to store the data, and what additional actions to take (e.g., providing hearing protection, maintaining adequate distance between patrons and the sound system, or providing quiet rest areas) [2].

In 2020 a systematic literature review was realized for MLS [3], including a historical overview. The first law concerning audience exposure and hearing damage risk mitigation came into effect in Switzerland in 1999, followed by Sweden in 2004, Germany in 2007, and several other European countries. The German rules are framed as an industry norm (DIN - German Institute for Standardization), which is not enforced, but concert and event promoters are liable for hearing damage sustained during a specific concert or event and consequentially need to measure and document sound levels to demonstrate compliance with the norm [4].

Another approach to this issue emerged in the Netherlands in 2013 where a sound level maximum was adopted in a covenant between the health department, hearing protection agencies, and event industry [5, 6]. Most of these rules stipulate a maximum A-weighted equivalent continuous sound level $\left(\mathrm{L}_{\text {Aeq }}\right)$ of or around $100 \mathrm{~dB} \mathrm{~L}$ Aeq,60min (Table 1). The use of $100 \mathrm{~dB}$ can be traced back to a recommendation made by the WHO in 1999 [7]. Some jurisdictions have added a shorter, secondary limit (such as $102 \mathrm{~dB} \mathrm{~L}_{\text {Aeq, } 15 \text { min }}$ in the Flemish region of Belgium) to allow for the dynamic range that is common at pop music concerts and events [5].

Discrepancies emerge when considering when, where, and how to measure, monitor, and document sound levels. In several countries the expectation is that the measurement microphone is positioned at the front of house mix position $(\mathrm{FOH})$, whereas in other countries the measurement must take place in, or in reference to, the loudest position that is accessible to the audience. Few of these rules have been systemically evaluated, and data regarding infringement is only available anecdotally.

\section{LIVE SOUND ENGINEERS SURVEY}

A survey was designed as an industry practitioners' consultation regarding experiences with and preferences for

\footnotetext{
${ }^{2}$ The German value differs in that it is averaged in blocks of 30 min and not a running average.
}

sound level monitoring and management practices. Sound Levels in Music Venues, a survey of Live Sound Engineers ran from July to September 2020, targeting live sound professionals worldwide, with ethics approval from the $\mathrm{Na}-$ tional Acoustic Laboratory, the research division of Hearing Australia. Qualtrics (Qualtrics, Provo, UT) was used as the survey platform and SPSS 27 (IBM, New York, NY) for statistical analysis. To maximize reach, the survey was translated into Mandarin, Portuguese, Spanish, and French. Questions were directly informed by discussions at the MLS meeting in 2020, where the development of a global standard was central on the agenda.

To contextualize respondents' answers, related topics were surveyed including demographics, education level, hearing health, familiarity with key technical terms, experience with sound level monitoring and management practices, and attitudes toward sound level regulations. The survey also assessed the desirability of a certification system for LSEs, specifically concerning the measurement and management of sound levels at entertainment events. This last topic, as well as the educational topics, surveyed were previously presented in an Audio Engineering Society Education Conference paper [8].

\subsection{Survey Response: Demographics}

Out of 2,389 responses, 1,651 were complete. Of the incomplete survey responses, 84 were $80 \%$ or more complete and therefore included in the analysis. The survey system disambiguates between "skipped" (the respondent did not answer the question) and "system missing" (the respondent ended the survey before the question).

Overall, the 1,735 responses considered complete spanned 63 countries. More than half came from three countries: the UK (409, 23.6\%), Brazil (295, 17.0\%), and USA $(213,12.3 \%)$. The next quartile consisted of Norway (101, $5.8 \%)$, Australia $(76,4.4 \%)$, Germany $(65,3.7 \%)$, Finland $(61,3.5 \%)$, and Switzerland (42, 2.4\%). Some of the world's largest countries had relatively low response rates, such as China $(36,2.1 \%)$ and India (11, 0.7\%).

As the data indicates, there is no relation between a nation's population size and the number of responses. The gender imbalance for the LSE profession is well documented $[9,10]$. From the completed responses $93.6 \%$ of respondents selected male, $4.2 \%$ female, $0.7 \%$ nonbinary, and $1.3 \%$ preferred not to say. The responses from China stood out with this question; from the 36 responses onequarter (9 respondents) selected female. From several countries including Belgium and the Netherlands, there were no respondents who selected female.

\subsubsection{Age and Professional Tenure}

Age was surveyed in bands of five years ranging from below 20 to over 60 . The $31-35$ age band (18\%) was the largest group, followed by 36-40 (16\%), 41-45 (13.1\%), and $25-30(12.5 \%)$. Professional tenure was surveyed in steps of five years, up to 15 years and over (Table 2). Nearly half of the respondents had worked as an LSE for more than 15 years (49\%), which was more than double the number 
Table 2. Age and professional tenure $(\mathrm{pn}=$ prefer not to say, no response $n=3$ ).

\begin{tabular}{lllllll}
\hline \multicolumn{7}{c}{ Tenure (years) } \\
& & $<5$ & $5-10$ & $10-15$ & $>15$ & Total \\
\hline \multirow{2}{*}{ Age } & $<20$ & 33 & 6 & 0 & 0 & 39 \\
& $21-25$ & 73 & 75 & 7 & 0 & 155 \\
& $26-30$ & 30 & 139 & 49 & 3 & 221 \\
& $31-35$ & 24 & 78 & 146 & 58 & 306 \\
& $36-40$ & 12 & 28 & 89 & 145 & 274 \\
& $41-45$ & 5 & 13 & 30 & 177 & 225 \\
& $46-50$ & 2 & 10 & 12 & 165 & 189 \\
& $51-55$ & 7 & 1 & 6 & 140 & 154 \\
& $56-60$ & 2 & 0 & 2 & 78 & 82 \\
& $>60$ & 0 & 3 & 4 & 77 & 84 \\
Total & pn & 0 & 1 & 0 & 2 & 3 \\
& & 188 & 354 & 345 & 845 & 1,732 \\
\hline
\end{tabular}

Table 3. Response data: In your opinion, which sound level metrics are most suitable for prescribing sound level limits? Other: a combination (please describe).

\begin{tabular}{lllll}
\hline & & $n$ & $\%$ & Valid \% \\
\hline Valid & $\mathrm{L}_{\text {Aeq }}$ & 745 & 42.9 & 50.4 \\
& $\mathrm{~L}_{\text {Ceq }}$ & 235 & 13.5 & 15.9 \\
& $\mathrm{~L}_{\text {Amax }}$ & 89 & 5.1 & 6.0 \\
& L $_{\text {Cpeak }}$ & 125 & 7.2 & 8.5 \\
& Other & 285 & 16.4 & 19.3 \\
\multirow{4}{*}{ Missing } & Total & 1,479 & 85.2 & 100.0 \\
& Skipped & 65 & 3.7 & \\
\multirow{7}{*}{ Total } & System & 191 & 11.0 & \\
& Total & 256 & 14.8 & \\
\hline
\end{tabular}

of respondents who indicated 5-10 (20\%) or 10-15 (20\%) years of professional experience.

\subsection{Sound Pressure Level Monitoring Preferences}

As indicated previously, central to the survey was the question regarding what LSEs around the world prefer when considering the specific variables within the $\mathrm{L}_{\mathrm{eq}}$ sound level monitoring procedure (Table 3).

Responses to "Other, e.g., a combination" included: Aweighted $\mathrm{L}_{\text {eq }}\left(\mathrm{L}_{\text {Aeq }}\right)$ and $\mathrm{C}$-weighted $\mathrm{L}_{\text {eq }}\left(\mathrm{L}_{\mathrm{Ceq}}\right)(\mathrm{n}=49)$, $\mathrm{L}_{\mathrm{Aeq}}$ and $\mathrm{C}$-weighted peak SPL $\left(\mathrm{L}_{\text {Cpeak }}\right)(\mathrm{n}=37)$, and "all four" $(\mathrm{n}=25)$. More detailed written responses pointed to the need for metrics for different situations, such as C-weighting for environmental noise $(n=27)$ and adaptive approaches to different musical genres $(n=15)$ since some genres are typically mixed with significantly more energy in the $\mathrm{C}$-weighted spectrum. A few $(n=4)$ respondents mentioned $\mathrm{B}$-weighting as an alternative to the common combination of $\mathrm{A}$ and $\mathrm{C}$-weighting.

What followed was a question about the preferred $\mathrm{L}_{\mathrm{eq}}$ time frame (Table 4). The responses to "a combination" included answers such as: "depends on the situation" ( $n$ $=23$ ), combinations of $15 \mathrm{~min}$ with longer times [e.g., 30 min, $60 \mathrm{~min}$, or the event duration (T), $n=21]$, combinations of 1 min with a longer time frame [e.g., 5, 15, or 30 $\min (n=18)$ ], and multiple (three or more) time frames
Table 4. Response data: In your opinion, what is the most useful averaging time frame for monitoring sound levels at $\mathrm{FOH}$ position? Other: a combination (please describe).

\begin{tabular}{lllll}
\hline & & $n$ & $\%$ & Valid \% \\
\hline Valid & $15 \mathrm{~min}$ & 522 & 30.1 & 34.0 \\
& $5 \mathrm{~min}$ & 311 & 17.9 & 20.3 \\
& $3 \mathrm{~min}$ & 210 & 12.1 & 13.7 \\
& Other & 139 & 8.0 & 9.1 \\
& 1 min & 135 & 7.8 & 8.8 \\
& $30 \mathrm{~min}$ & 112 & 6.5 & 7.3 \\
& 60 min & 73 & 4.2 & 4.8 \\
& Skipped & 32 & 1.8 & 2.1 \\
Missing & Total & 1,534 & 88.4 & 100.0 \\
Total & System & 201 & 11.6 & \\
\hline
\end{tabular}

Table 5. Cross-tabulation of measurement metrics (horizontal) vs. time base (vertical) (missing $n=201$, total $n=1735$ ). Chi square: $\chi^{2}(35)=735.553, p<0.001$. The effect size is medium (Cramer's V $=0.310, p<0.001)$.

\begin{tabular}{llllllll}
\hline & $\mathrm{L}_{\text {Aeq }}$ & $\mathrm{L}_{\text {Ceq }}$ & $\mathrm{L}_{\text {Amax }}$ & $\mathrm{L}_{\text {Cpeak }}$ & Other & Skip & Total \\
\hline $1 \mathrm{~min}$ & 43 & 24 & 18 & 20 & 25 & 5 & 135 \\
$3 \mathrm{~min}$ & 88 & 42 & 17 & 34 & 21 & 8 & 210 \\
$5 \mathrm{~min}$ & 148 & 56 & 21 & 25 & 52 & 9 & 311 \\
$15 \mathrm{~min}$ & 312 & 76 & 18 & 31 & 72 & 13 & 522 \\
$30 \mathrm{~min}$ & 65 & 21 & 7 & 5 & 13 & 1 & 112 \\
$60 \mathrm{~min}$ & 44 & 7 & 2 & 3 & 17 & 0 & 73 \\
Other & 40 & 8 & 4 & 3 & 81 & 3 & 139 \\
Skip & 2 & 1 & 0 & 1 & 2 & 26 & 32 \\
Total & 742 & 235 & 87 & 122 & 283 & 65 & 1,534 \\
\hline
\end{tabular}

Table 6. Response data: Have you worked with any of these noise measurement tools? (Tick all that apply).

\begin{tabular}{lll}
\hline & $n$ & $\%$ \\
\hline Sound Level Meter & 1,443 & 85.6 \\
10EaZy system & 513 & 30.4 \\
MeTrao system & 138 & 8.2 \\
WaveCapture RC3 system & 238 & 14.1 \\
Smaart system & 1,335 & 79.2 \\
Simple traffic light system & 729 & 43.2 \\
Total & 4,396 & 260.7 \\
\hline
\end{tabular}

including $\mathrm{T}(n=11)$. A 10-min time frame was mentioned by respondents $(n=7)$.

\subsubsection{Cross-Tabulation of Sound Level Metrics}

Cross-tabulation of the two sound level metric questions reveals an association between preferred weighting and time frame (Table 5). $\mathrm{L}_{\text {Aeq, } 15 \min }$ was most selected $(n=$ 312), followed by $\mathrm{L}_{\text {Aeq, } 5 \min }(n=148)$.

\subsection{Sound Pressure Level Measurement Tools}

The survey asked which sound level measurement and management system(s) respondents had worked with through a multiple response ("tick all that apply") question (Table 6).

When analyzing responses per country (Table 7, for brevity countries with fewer than 30 responses were ex- 
Table 7. Measurement tools cross-tabulated per country $(n>30)$. (Chi square cannot be used for such questions.)

\begin{tabular}{llllllll}
\hline & Sound Level Meter & 10EaZy & MeTrao & WaveCapture & Smaart & Traffic Light & Total \\
\hline Argentina & 20 & 1 & 0 & 0 & 19 & 8 & 22 \\
Australia & 73 & 16 & 3 & 9 & 47 & 45 & 74 \\
Brazil & 242 & 8 & 5 & 10 & 200 & 31 & 277 \\
Canada & 30 & 2 & 2 & 4 & 26 & 10 & 34 \\
China & 28 & 2 & 2 & 2 & 15 & 6 & 36 \\
Denmark & 37 & 55 & 3 & 13 & 49 & 21 & 63 \\
Finland & 51 & 19 & 0 & 2 & 58 & 26 & 61 \\
France & 37 & 14 & 1 & 3 & 35 & 23 & 39 \\
Germany & 48 & 30 & 8 & 5 & 46 & 28 & 64 \\
Neth. & 20 & 18 & 23 & 0 & 83 & 10 & 30 \\
Norway & 56 & 67 & 9 & 57 & 28 & 17 & 97 \\
Switz. & 39 & 20 & 4 & 2 & 326 & 295 & 42 \\
UK & 366 & 154 & 49 & 79 & 180 & 82 & 405 \\
USA & 198 & 53 & 9 & 22 & 1,132 & 642 & 210 \\
Total & 1,245 & 459 & 118 & 208 & 1,454 \\
\hline
\end{tabular}

cluded) it can be observed that specialized tools such as 10EaZy (Denmark), MeTrao (the Netherlands), and WaveCapture (Norway; this firm has ceased operations since the end of 2020) are commonplace in Northwestern Europe but are less common elsewhere. This can be explained by the fact that specialized regulations regarding sound levels in music venues (different than environmental noise regulations) are generally found in Europe [1].

The uptake of Smaart (Rational Acoustics, Woodstock, CT) is promising; however, since the program performs a variety of sound system analysis functions, we cannot be certain how many respondents used its SPL measurement features specifically. ${ }^{3}$ Furthermore, this software is often used for transfer function measurement, for which calibration is not necessary, and therefore not necessarily indicative of the presence of a calibrated SPL measurement tool.

\subsection{Confidence}

To assess respondents' understanding of typical parameters in use for sound level measurements, they were asked to rate their confidence using seven different metrics (Fig. 1). The order of these terms was not randomized in the survey, which may have introduced some bias.

\subsubsection{Predicting Confidence Using Statistical Regression}

Averaging was used to compute a new variable that expresses the mean confidence using relevant metrics for each respondent. This variable was used in a linear regression to find which of the surveyed variables can predict a greater level of average confidence (Table 8). Variables included questions about the venue size (in terms of audience capacity) respondents worked in most of the time, professional tenure, level of general education, experience with specific SLM (sound level meter) tools (including whether such

\footnotetext{
${ }^{3}$ Smaart can be used with 10EaZy measurement hardware, but that combination was not surveyed as such. A stand-alone SPL measurement only version of Smaart was released in 2020, which was also not covered in this survey.
}

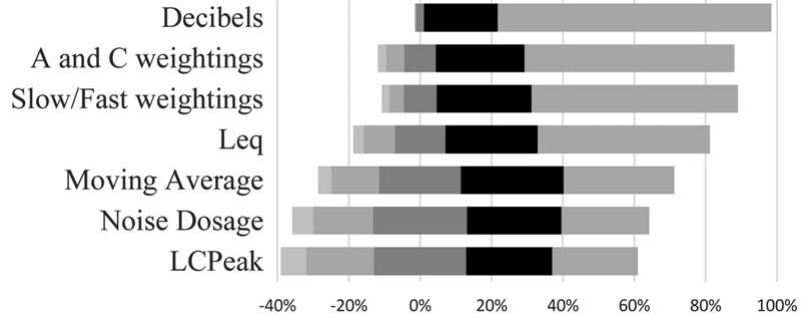

Fig. 1. Respondents' confidence using key metrics $(n=1,715)$ Divergent stacked bars, left to right: not at all confident, not confident, neutral, confident (black), and very confident. For example, a majority of respondents are confident using decibels but just over $20 \%$ are confidently using the term $\mathrm{L}_{\mathrm{CPeak}}$.

Table 8. Average confidence using sound level metrics. Linear regression: $\mathrm{R}^{2}=0.302, \mathrm{~F}(8,1220)=65.862, p<0.001$.

\begin{tabular}{|c|c|c|c|c|c|}
\hline \multicolumn{3}{|c|}{ Unstandardized Coefficients } & \multicolumn{3}{|c|}{$\begin{array}{l}\text { Standardized } \\
\text { Coefficients }\end{array}$} \\
\hline & B & $\begin{array}{l}\text { Std. } \\
\text { Error }\end{array}$ & Beta & $\mathrm{t}$ & Sig. \\
\hline (Constant) & 2.886 & 0.077 & & 37.280 & 0.000 \\
\hline Calibrate $\mathrm{Y} / \mathrm{N}$ & 0.422 & 0.042 & 0.255 & 9.990 & 0.000 \\
\hline Smaart Y/N & 0.284 & 0.048 & 0.153 & 5.913 & 0.000 \\
\hline 10eazy Y/N & 0.208 & 0.040 & 0.135 & 5.162 & 0.000 \\
\hline $\begin{array}{l}\text { Worked with } \\
\text { "Sound Guard" }\end{array}$ & 0.225 & 0.040 & 0.151 & 5.595 & 0.000 \\
\hline $\begin{array}{l}\text { Highest level of } \\
\text { general } \\
\text { education }\end{array}$ & 0.169 & 0.030 & 0.138 & 5.706 & 0.000 \\
\hline $\begin{array}{l}\text { Tenure > } 15 \\
\text { years }\end{array}$ & 0.114 & 0.037 & 0.078 & 3.041 & 0.002 \\
\hline $\begin{array}{l}\text { Venue } \\
2,000-10,000\end{array}$ & 0.114 & 0.049 & 0.078 & 2.332 & 0.020 \\
\hline Venue $>10,000$ & 0.070 & 0.047 & 0.048 & 1.471 & 0.141 \\
\hline
\end{tabular}

tools are calibrated), and whether respondents had ever worked with a "Sound Guard." A Sound Guard is a sound level monitoring specialist usually engaged by event promotors to liaise between stakeholders before, during, and 


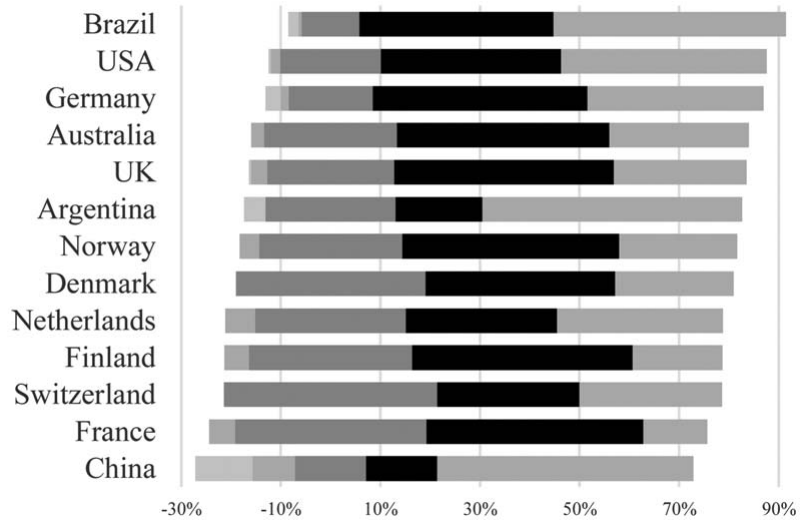

Fig. 2. Response data: I consider that I am more aware of my exposure to high sound levels than other sound engineers. $n=$ 1,488. Divergent stacked bars, left to right: strongly disagree, disagree, neutral, somewhat agree (black), and strongly agree. Overall we see that respondents from Brazil consider themselves more aware than others in comparison to all other countries in the survey data.

after events to ensure sound levels stay within the limit specified in a license [11].

Variables that positively contribute to respondents' average confidence include whether respondents calibrate their SLM, have experience with the specialized software tools Smaart or 10eaZy, and have worked with a Sound Guard. Less important predictors are whether respondents have a postgraduate education, have a tenure greater than 15 years, and are working mostly in medium to large-size venues. Working in the largest category of venue size was shown to be insignificant as a confidence predictor.

\subsection{Attitude}

Several questions throughout the survey were included to gauge respondents' attitudes toward sound level exposure and the relevant regulation. The first question was phrased to allow comparison to peers about awareness of sound exposure risks. Interestingly, responses to this question tended to be similar among respondents from the same country and were not correlated with any other survey questions such as education or tenure (Fig. 2). This suggests that answers to these questions are more likely to reveal cultural and national differences rather than professional attitudes.

A Kruskal-Wallis test indicated significant differences in the responses from different countries $[\mathrm{H}(13)=72.285$, $p<0.001$ ], and pairwise comparisons showed statistically significant differences between the USA and UK and between Brazil and the UK, Norway, Switzerland, Denmark, Finland, and France.

\subsubsection{Responsibility}

A further attitude question was phrased around responsibility (Fig. 3).

When analyzing the response per country (again $n>30$ ), the greatest differences emerged when considering the audiences' own responsibilities (Fig. 4). In Switzerland, Finland, and USA, respondents strongly agree with the state-

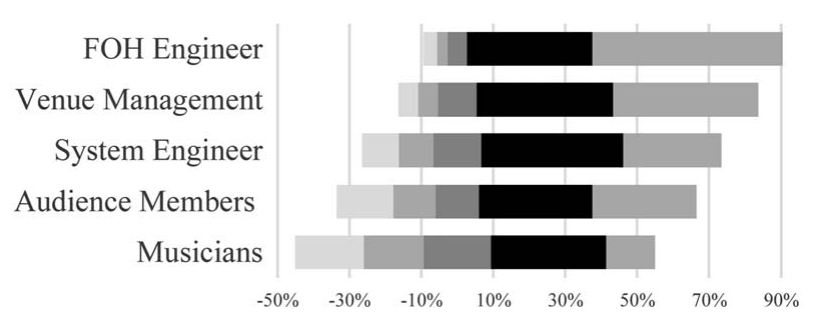

Fig. 3. Response data: Who is responsible for protecting audience members' hearing at music concerts and events? Likert scales left to right: strongly disagree, disagree, neutral, agree (black), and strongly agree. Note: neutral category split to create divergent stacked bar chart. Most respondents agree that FOH engineers are responsible for audience members' hearing and musicians are least responsible.

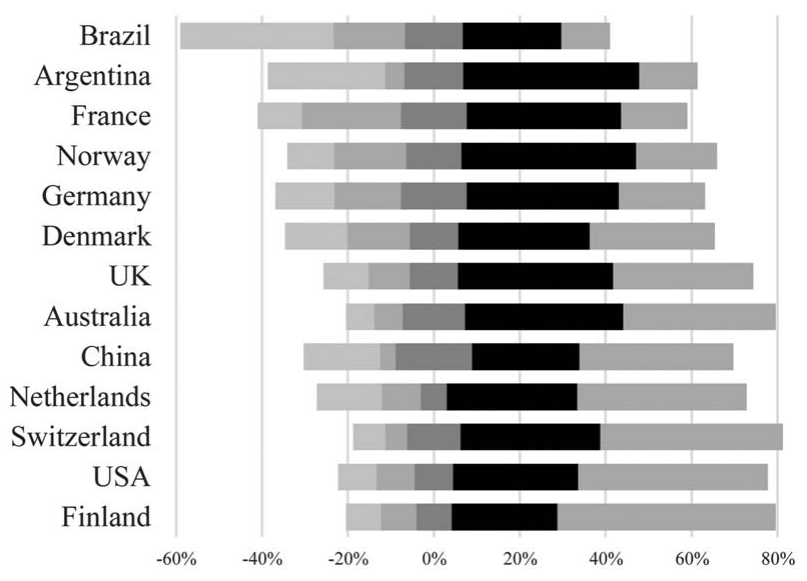

Fig. 4. Response data: Who is responsible for protecting audience members' hearing at music concerts and events? Audience Members, response per country. Divergent stacked bars, left to right: strongly disagree, disagree, neutral, somewhat agree (black), and strongly agree.

ment that audience members should be responsible. On the other hand, in Brazil most respondents disagreed with this statement. A Kruskal-Wallis test indicated that the difference between Brazil and the other countries listed, barring France and Argentina, is significant: $\mathrm{H}(13)=166.756, p<$ 0.001 .

\subsubsection{Certification}

Certification was the topic of an earlier publication [8] but is worth outlining here as an indicator of the scale of support for centralized approaches to issues related to sound levels in music venues. Respondents were asked, again in five-step Likert scales, to indicate their feelings regarding three statements about certification for LSEs (Fig. 5).

\subsection{Analysis and Discussion}

The survey outcome has limitations, with nearly half of the responses coming from only three countries. There is no registry of LSEs, and deriving numbers of sound engineers in each country is guesswork at best. Great effort notwithstanding, the authors' combined professional and academic networks did not connect to a great number of engineers 


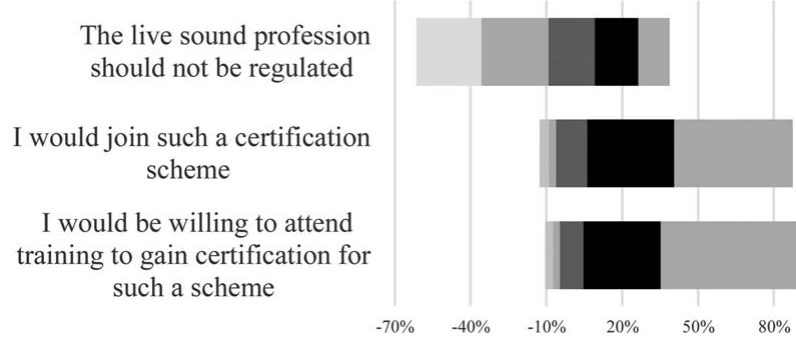

Fig. 5. Support (count) for a certification scheme $(n=1,629)$. Left to right: strongly disagree, disagree, neutral, somewhat agree (black), and strongly agree. Respondents are divided whether the profession should be regulated, but those in favor are positive about signing up to a certification scheme and/or training to join such a scheme.

in large countries such as India, China, or Indonesia. The number of responses per country varied greatly, for example 19 responses per million population from Norway (5.3 million), 6 responses per million population from the UK and Northern Ireland (67 million), and 1 response per million population from Brazil (211 million). Consequentially, strong conclusions cannot be drawn here.

Despite these limitations, the survey outcomes do represent a wide range of LSEs at different levels within the industry, with varying levels of knowledge and experience. Analyses found no significant correlations between the sound level metrics questions $\left(\mathrm{L}_{\mathrm{eq}}\right.$-weighting and time frame) and other surveyed variables such as tenure, education and training, attitudes toward health, or country.

The survey does indicate, however, a strong desire among for an $\mathrm{L}_{\text {Aeq }}$ integration time frame of $15 \mathrm{~min}$ or less and the use of $\mathrm{L}_{\text {Aeq }}$ as the primary weighting (see Tables 4 and 5). Another notable outcome is strong support for a certification scheme for LSEs in the field of sound level monitoring, which reflects the strong sense of responsibility LSEs demonstrate in managing and controlling sound levels.

\section{REAL-WORLD DATA ANALYSIS}

While sound level regulations are often developed and implemented with a focus on minimizing risks to the audience and annoyance to the local community, it is critical to understand how regulations (as well as sound level monitoring practice) can affect the engineering and listening experience at a live event. While audience safety is critical to support, it is also important to avoid regulations that detract from the audience experience, namely in terms of overall sound pressure level and musical dynamics. Central to this is providing timely and meaningful information to the sound engineer to facilitate their job to simultaneously achieve a "democracy of sound" (high-quality audio in every seat in a venue) while complying with local sound level regulations.

Three datasets (A, B, and C) of live event sound level measurements exist from the authors' previous work: (A) 23 performances across two stages at a music festival in the USA [12], (B) 130 performances over a 5-year period
Table 9. Macro analysis of live event datasets A (single music festival) and B (five years from an international touring act). Gray cells represent statistically weak relationships $(p>0.05)$. Dataset $B$ uses $\mathrm{L}_{\mathrm{eq}, 1 \mathrm{~min}}$ data, rather than the ideal $\mathrm{L}_{\mathrm{eq}, 1 \mathrm{~s}}$ data, making live dynamic range (LDR) analysis less accurate.

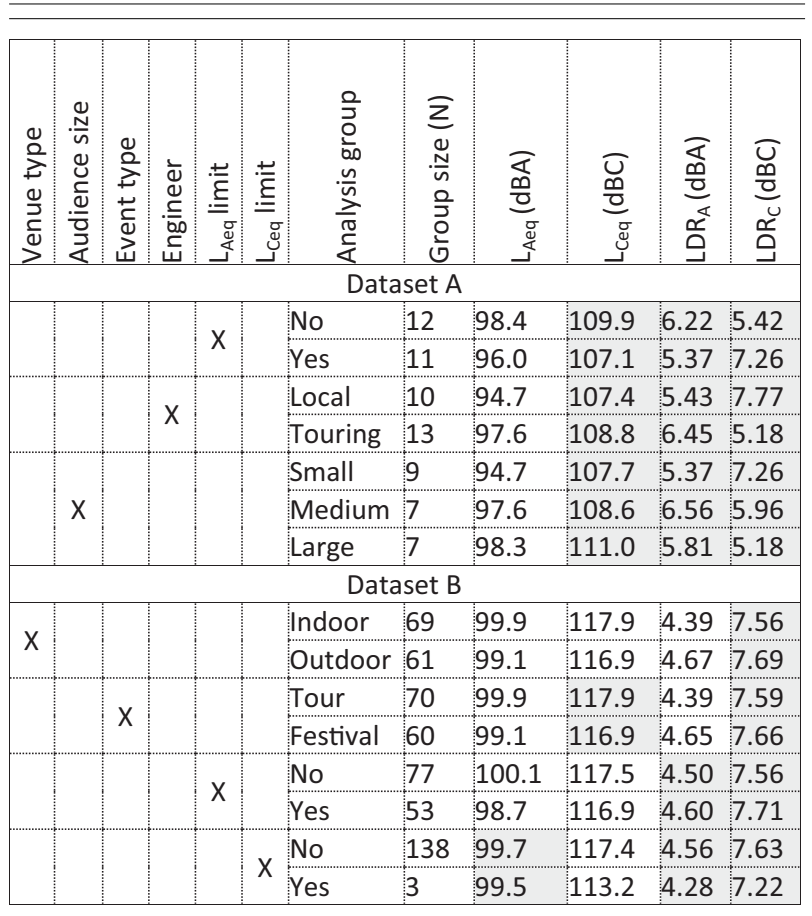

(tour dates and festivals) from an international touring act [13], and (C) 137 performances within a single year (tour dates and festivals) in the Netherlands and Belgium [11]. While all datasets have been analyzed in previous research, a partial re-analysis will be conducted here, leading to a comprehensive inspection of the effect that sound exposure regulations and monitoring practice can have on sound levels and musical dynamics at live events.

\subsection{Macro Analysis}

Datasets A and B allowed for a macro analysis with variables including (the presence of) $\mathrm{L}_{\mathrm{Aeq}}$ or $\mathrm{L}_{\mathrm{Ceq}}$ limits, type of sound engineer (touring or local), size of the audience (small, medium, or large), type of venue (indoor or outdoor), and type of event (tour or festival). The results are presented in Table 9. To determine which variety of test was appropriate, all data were tested in MATLAB (The MathWorks Inc., Natick, MA) to see if they were normally distributed. Anderson-Darling tests were used for this purpose. In all cases, the data was found to be normally distributed, meaning that an analysis of variance test would be appropriate. The null hypothesis for all tests was that there was no significant difference in the statistic under inspection due to the variable(s) under test.

First, it is useful to inspect factors affecting sound levels, which are unrelated to regulations. At the large outdoor music festival in dataset A, roughly half of the 23 performances were mixed by touring engineers, and the other half were mixed by the local system engineers. Touring engi- 
neers were found to mix at an average $L_{\text {Aeq, } 1 \mathrm{~s}}$ nearly $3 \mathrm{dBA}$ above the local engineers $(p=0.006)$. The local engineers were directly answerable to the event management for any sound level infringements, and these engineers worked for the sound system provider, hence would be less inclined to drive the system to its limits. While a similar trend was observed for $\mathrm{L}_{\mathrm{Ceq}, 1 \mathrm{~s}}$, the findings were not significant $(p=$ $0.138)$.

Crowd size was tracked across the duration of the music festival in dataset $A$, which was found to be a significant factor ( $p=0.0454)$ for $\mathrm{L}_{\text {Aeq, } 1 \mathrm{~s}}$. This indicates that sound engineers respond to varying crowd size, reducing playback level for smaller audiences that are concentrated closer to the stage. No such effect was found for $L_{C e q, 1 s}$, which can be explained by the subwoofer system being controlled by a separate fader on the mixing desk in this instance. A comprehensive analysis of this dataset has been previously presented in [12].

Dataset B (drawn from five years of data collected by the same sound engineer touring with an international touring act) covers dedicated tour date performances and sets at music festivals. The majority of tour dates were indoors, and all but one festival was outdoors, hence the similarity in the statistics between these two. The indoor events were consistently $1 \mathrm{~dB}$ higher in $\mathrm{L}_{\mathrm{Aeq}}, 1 \mathrm{~min}$ and $\mathrm{L}_{\mathrm{Ceq}, 1 \mathrm{~min}}$ ( $p<0.001$ and $p=0.0128$, respectively). This can be attributed to the effect of room acoustics for indoor venues. The act has notoriously high stage levels, hence an identified correlation between overall sound level and venue size (as identified in a previous study [13]) due to the engineer having to increase the main sound system's level to overcome to excessive sound levels from the stage and the venue's acoustic response. A previous study [13] identified the quality of acoustic design of indoor venues as critical to facilitate adherence to local sound level regulations while maintaining a high-quality listening experience. It should be noted that the indoor/outdoor (and consequently the tour date/festival analysis) was the only category found to significantly influence A-weighted musical dynamics ( $p$ $=0.002$ ). Again, this can be attributed to room acoustics for indoor venues, where live dynamic range (LDR) [14] was noticeably lower indoors due to masking effects from the room acoustics.

Fifty-three out of the 130 events included within dataset $\mathrm{B}$ had $\mathrm{L}_{\text {Aeq }}$ sound level limits in place. The presence of such a limit was shown to significantly influence $\mathrm{L}_{\text {Aeq, } 1 \text { min }}(p<$ $0.001)$ in a similar manner seen in dataset $A$. The presence of an $\mathrm{L}_{\text {Aeq }}$ limit also resulted in $\mathrm{L}_{\mathrm{Ceq}, 1 \mathrm{~min}}$ to be roughly $1 \mathrm{~dB}$ lower $(p=0.011)$. Three out of 130 events within dataset $B$ had $L_{C e q}$ limits in place. Having such a limit in place significantly influenced $\mathrm{L}_{\mathrm{Ceq}, 1 \mathrm{~min}}(p<0.001)$, but the sparsity of the dataset in this regard makes this a weak conclusion.

\subsection{Micro Analysis}

The three datasets (A, B, and C) cover a wide variety of sound level regulations in terms of $\mathrm{L}_{\mathrm{eq}}$ limit and time frame. This allows for a micro analysis inspecting the effect of spe- cific regulations on overall sound level, musical dynamics, and limit violations. First, an analysis of the datasets can be carried out based on the effect of specific $L_{\text {Aeq }}$ limits and time frames on average $L_{\text {Aeq, } 1 s}$ (relative to the limit) and $\mathrm{L}_{\text {Ceq,1s }}$ (Fig. 6).

The observed trend for the $\mathrm{L}_{\text {Aeq, 1s }}$ shows that lower level limits and longer time frames permit higher short-term sound levels. With time frames greater than $15 \mathrm{~min}$, the sound engineer will not receive timely information of a potential limit violation. This delayed response has the potential to cause higher levels relative to the imposed limit. This can be observed by analyzing the data in relation to the limit (Fig. 7).

The left plot in Fig. 7 supports the idea that a combination of lower limits and longer time frames results in greater level violations, although time above the limit does not necessarily indicate a level violation, since the analysis is based on $\mathrm{L}_{\mathrm{Aeq}, 1 \mathrm{~s}}$ data rather than data using the imposed time frame. This analysis reveals that longer integration times have the potential to allow the engineer to utilize greater musical dynamic range in the performance without risking a level violation.

The raw 1-s or 1-min data from each event was processed with its specific $\mathrm{L}_{\mathrm{eq}}$ time frame (shown on the right plot in Fig. 7) to give indication of the nature of any level violation. Over the 301 performances covered by the three datasets, there was not a single instance of $\mathrm{L}_{\mathrm{Aeq}, \mathrm{T}}$ being more than 1 $\mathrm{dBA}$ over the limit on average (there may have been short instances of higher level violations, but this analysis looks at the average level of limit violation). The events with the greatest average level violation have either very short (1 or $5 \mathrm{~min}$ ) time frames or low limits (98 dBA or lower). Most events show insignificant limit violations, indicating that the engineers were working to comply with the local regulations.

A similar analysis was performed by inspecting the effect of specific $\mathrm{L}_{\mathrm{Ceq}}$ regulations (Figs. 8 and 9), with the primary conclusion that $\mathrm{L}_{\mathrm{Ceq}}$ limits of $110 \mathrm{~dB}$ present problems in terms of the ability to comply with the regulation, with limit violations identified up to $25 \%$ of an event's duration. The only higher limit levels showing any amount of violation were those using $5 \mathrm{~min}$, indicating such a time frame is too short (which agrees with the $\mathrm{L}_{\text {Aeq }}$ analysis). As with the $\mathrm{L}_{\text {Aeq }}$ analysis, A-weighted data (in relation to the $\mathrm{L}_{\mathrm{Ceq}}$ regulations) rises in level with the specific $\mathrm{L}_{\mathrm{Ceq}}$ limit. There is no observable effect of time frame in this regard.

Lastly, $\mathrm{L}_{\mathrm{Aeq}}$ and $\mathrm{L}_{\mathrm{Ceq}}$ regulations can be analyzed for an effect on musical dynamics (Figs. 10 and 11). LDR was used to quantify the musical dynamics without any influence from recorded data that was outside of the control of the sound engineer (crowd noise) and unrelated to the musical content of the performance (stage banter between songs and necessary overall level adjustments) [14].

The LDR data shows a slight upward trend with increasing $\mathrm{L}_{\text {Aeq }}$ level limit and integration time, where again, short integration times ( 5 min or less) can severely limit musical dynamics in a performance because of the engineer's limited ability to allow for the occasional amplitude peak. This effect from the $L_{\text {Aeq }}$ regulation is seen within the $A$ 

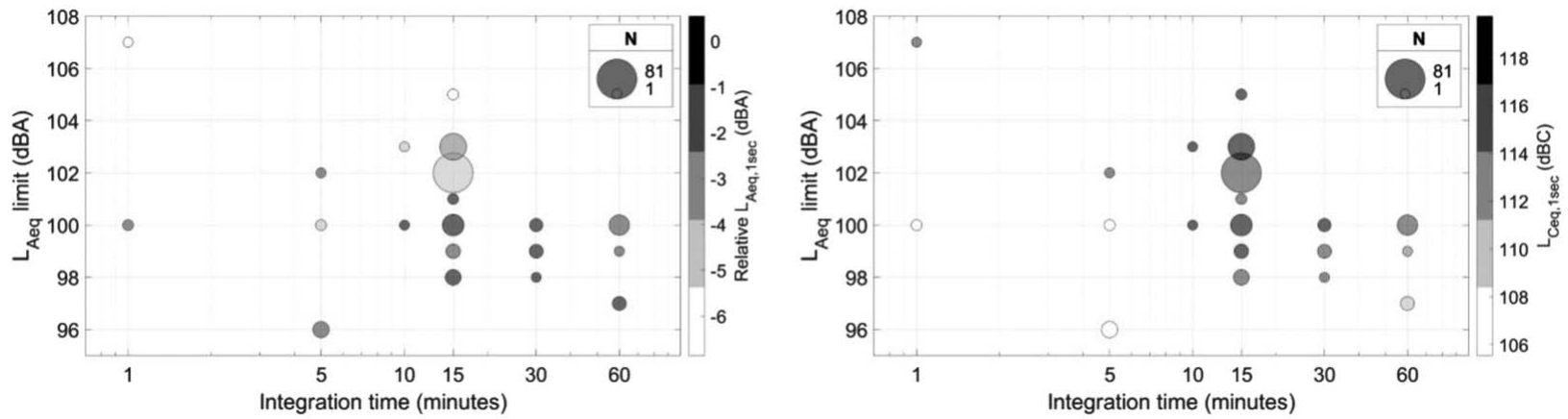

Fig. 6. Impact of $\mathrm{L}_{\text {Aeq }}$ regulations on $\mathrm{L}_{\text {Aeq, 1s }}$ (left, relative to the level limit) and $\mathrm{L}_{\mathrm{Ceq}, 1 \mathrm{~s}}$ (right). Bubble size represents number of instances of that specific regulation, and bubble shade represents the relative/absolute $\mathrm{L}_{\mathrm{eq}}$ according to the color scale as indicated.

and $\mathrm{C}$-weighted data. The $\mathrm{L}_{\mathrm{Ceq}}$ regulation analysis shows a similar trend for the $\mathrm{C}$-weighted data only, with higher level limits and longer integration times providing a greater amount of musical dynamics.

\section{CONCLUSIONS AND FURTHER WORK}

Combining three different analysis approaches, this paper reviews current regulations in place to limit the sound levels in music venues and events, either to reduce nuisance to neighbors or to reduce audiences' exposure to harmful sound levels. When reviewing the different limits set by such regulations it is easy to conclude that there is no standardization in approach or the specific metrics used to express SPL limits.

The survey of live sound engineers equally showed a great many different preferences toward such metrics; how- ever $\mathrm{L}_{\mathrm{Aeq}, 15 \mathrm{~min}}$, followed by $\mathrm{L}_{\text {Aeq,5min }}$, greatly stands out from other combinations. The survey also provided insight into the level of support from the live sound community worldwide to work with and adhere to sound level regulations.

At the same time, great differences can be seen in operational knowledge when it comes to understanding different metrics commonly in use, indicating that more can be done in education and training. The suggestion of a certification scheme for the currently unregulated live sound profession found great support from the survey respondents.

The support and willingness of many engineers to adhere to regulated maxima also emerges from the quantitative analysis of real-world sound level data. When considering the efficacy of regulation, where in place, the 15-min $\mathrm{L}_{\mathrm{eq}}$ integration time appears to be advantageous considering these three key observations stemming from this research:
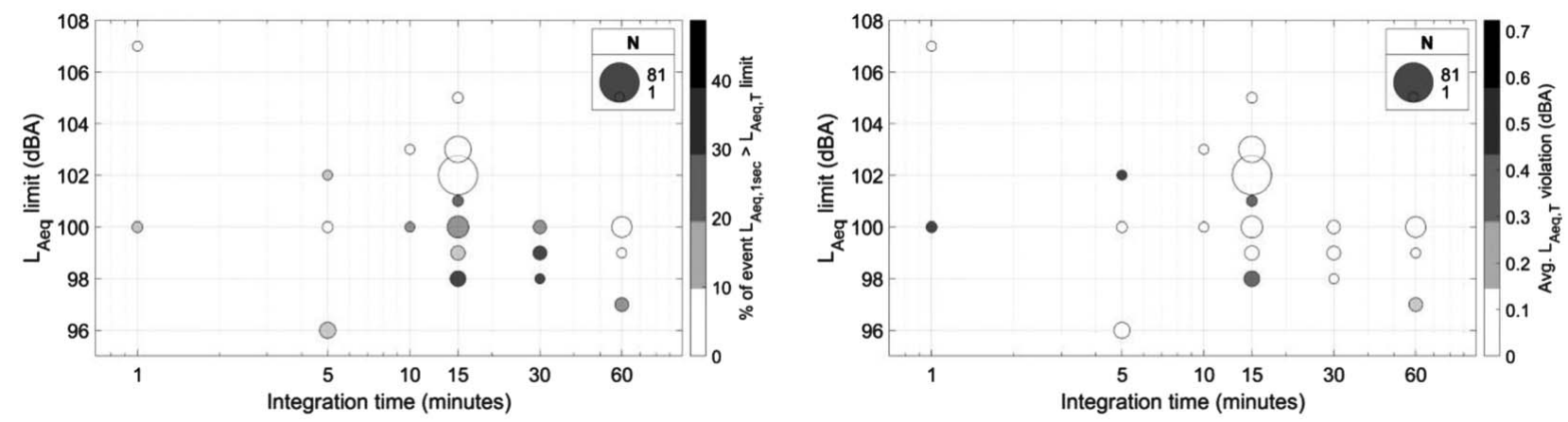

Fig. 7. $\mathrm{L}_{\text {Aeq }}$ regulations in terms of time that $\mathrm{L}_{\text {Aeq, } 1 \mathrm{~s}}$ was over the $\mathrm{L}_{\text {Aeq, }}$ limit (left) and average $\mathrm{L}_{\text {Aeq,T }}$ limit violation (right).
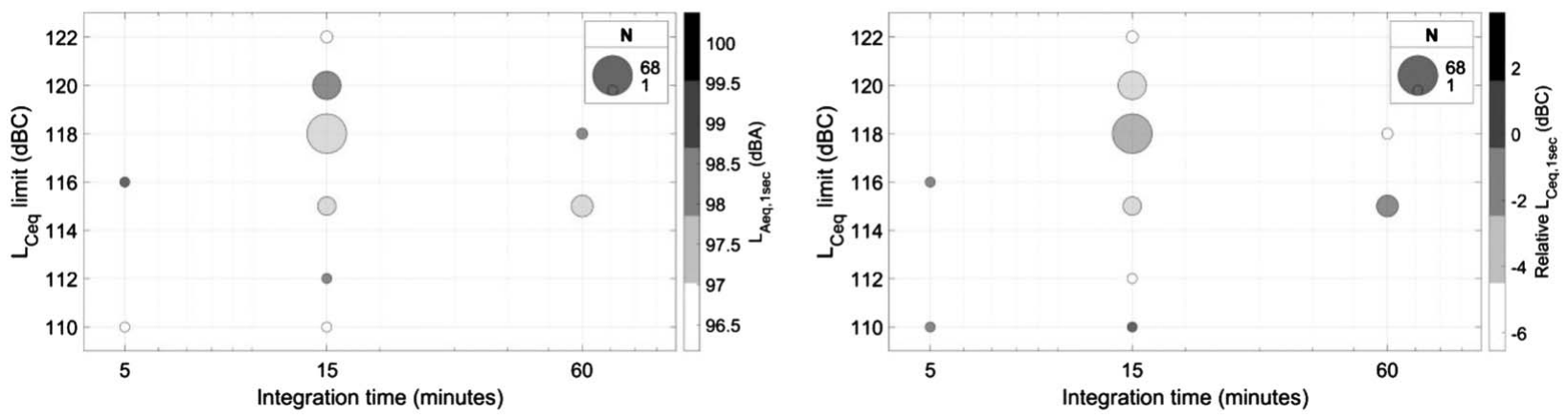

Fig. 8. Impact of $\mathrm{L}_{\mathrm{Ceq}}$ regulations on $\mathrm{L}_{\mathrm{Aeq}, 1 \mathrm{~s}}$ (left) and $\mathrm{L}_{\mathrm{Ceq}, 1 \mathrm{~s}}$ (right, relative to the level limit). 

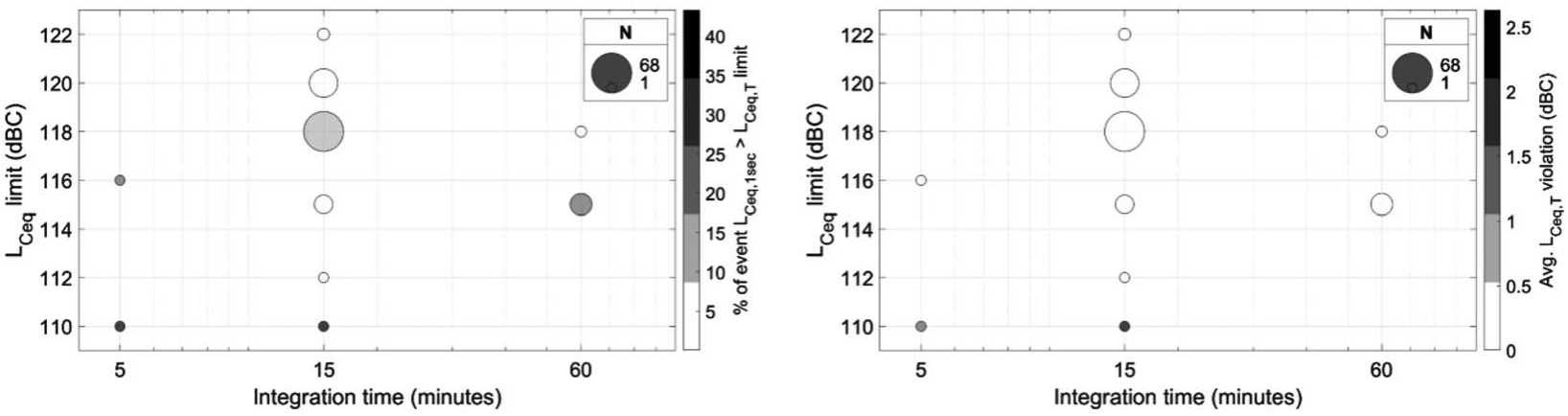

Fig. 9. $\mathrm{L}_{\mathrm{Ceq}}$ regulations in terms of time that $\mathrm{L}_{\mathrm{Ceq}, 1 \mathrm{~s}}$ was over the $\mathrm{L}_{\mathrm{Ceq}, \mathrm{T}}$ limit (left) and average $\mathrm{L}_{\mathrm{Ceq}, \mathrm{T}}$ limit violation (right).

1) Higher time frames allow for insufficient real time feedback to sound engineers as a concert progresses.

2) Higher time frames provide greater scope for sound engineers to explore a wider range of musical dynamics without risk of a level violation.

3) Lower time frames (specifically $5 \mathrm{~min}$ ), even when combined with lower limits, result in more violations (expressed as time spent above the regulation maximum).

The investigation of a certification system for LSEs, specifically allowing certified LSEs to demonstrate their ability to work with sound level maxima, was already mentioned. At the time of writing, the authors are contributing to the WHO MLS initiative, focusing on the formulation of a global standard, foreseen to be released in the first half of 2022. One of the greater challenges with sound level regulations is found in smaller venues where acoustics conditions are generally suboptimal, and whether a one-size-fits-all standard can be created that works in venues of any size remains a question. An earlier study looking at levels in seven small urban venues in Melbourne [15] is currently being replicated in similar venues in Perth, Australia, with a publication forthcoming.

Overall, the research presented in this paper reveals that live sound engineers are willing and able to provide a high-quality live music listening experience to audiences while simultaneously preventing excessive sound exposure or noise pollution. This is provided, however, that the sound level regulations in place do not overly restrict the engineer (as with low $\mathrm{L}_{\mathrm{eq}}$ maxima or short time frames), and the engineer has access to efficient and effective sound level monitoring and management education, tools, and advice. Improved sound level monitoring and management tools are the focus of the third and final paper in this series.
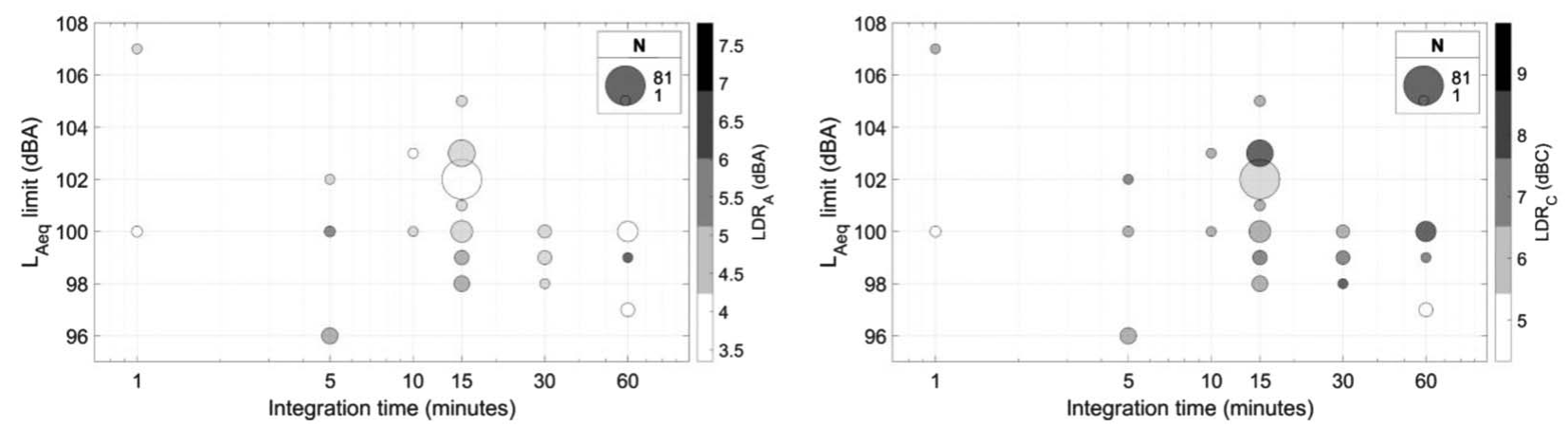

Fig. 10. Impact of $\mathrm{L}_{\text {Aeq }}$ regulations effects on musical dynamics (LDR) for A-weighted (left) and C-weighted (right) data.
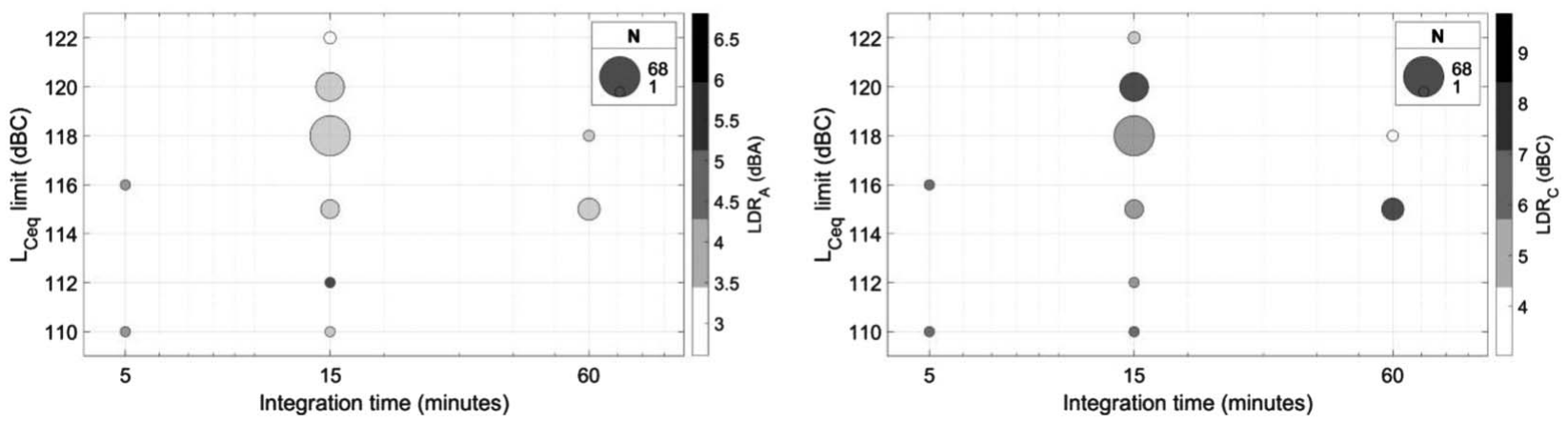

Fig. 11. Impact of $\mathrm{L}_{\mathrm{Ceq}}$ regulations effects on musical dynamics (LDR) for A-weighted (left) and C-weighted (right) data. 


\section{ACKNOWLEDGMENT}

We thank Dr. Elizabeth Beach for her help with the ethics approval process and design of the survey and Prof. Xander Lub for his help with the analysis.

\section{REFERENCES}

[1] A. J. Hill (chairman and editor), Understanding and Managing Sound Exposure and Noise Pollution at Outdoor Events. Audio Engineering Society Technical Document AESTD1007.1.20-05 (2020 May).

[2] E. F. Beach, R. Cowan, J. Mulder, and I. O'Brien, "Applying the Hierarchy of Hazard Control to Regulation of Sound Levels in Entertainment Venues," Ann. Work Expos. Health, vol. 64, no. 4, pp. 342-349 (2020 May). http://doi.org/10.1093/annweh/wxaa018.

[3] J. Mulder and S. McGinnity, "Sound Level Measurement, Monitoring, Management, and Documentation in Music Venues," Tech. Rep. (2020 May). https://cdn.who. int/media/docs/default-source/documents/health-topics/ deafness-and-hearing-loss/monograph-on-sound-levelmeasurement-management-and-documentation-in-musicvenues.pdf.

[4] M. Ebner and J. Knoll, Gehörgefährdung des Publikums bei Veranstaltungen: Kommentar zu DIN 15905-5 (Beuth Verlag, Berlin, Germany, 2019).

[5] J. Mulder, I. O'Brien, and R. Cowan E. F. Beach, "Overview of Laws and Regulations Aimed at Protecting the Hearing of Patrons Within Entertainment Venues," Eur. J. Public Health, vol. 31, no. 1, pp. 227-233 (2020 Oct.). http://doi.org/10.1093/eurpub/ckaa149.

[6] R. Cowan, E. F. BeachJ. Mulder, and I. O’Brien, "Regulations to Reduce Risk of Hearing Damage in Concert Venues," Bull. World Health Organ., vol. 98, no. 5, pp. 367369 (2020 Apr.). http://doi.org/10.2471/BLT.19.242404.

[7] B. Berglund, T. Lindvall, and D. H. Schwela (Eds.), Guidelines for Community Noise (World Health Organization, Geneva, Switzerland, 1999). https://www.who.int/ docstore/peh/noise/Comnoise-1.pdf.
[8] J. Mulder, A. Hill, J. Burton et al. "Education and Certification in Sound Pressure Level Measurement, Monitoring and Management at Entertainment Events," in Proceedings of the AES Audio Education Conference (2021 Jul.), paper 37.

[9] S. McGinnity, E. F. Beach, R. S. C. Cowan, and J. Mulder, "The Hearing Health of Live-Music Sound Engineers," Arch. Environ. Occup. Health, vol. 76, no. 6, pp. 301-312 (2020 Oct.). http://doi.org/10.1080/19338244. 2020.1828241.

[10] A. Jamieson, "Use of and Attitudes Towards Hearing Protection in the Sound and Music Industries: Results of a Pilot Survey," in Proceedings of the AES 58th International Conference on Music Induced Hearing Disorders (2015 Jun.), paper 1-2.

[11] M. Kok, "Sound Level Measurements \& Control at Large Dance Events," in Proceedings of the AES 58th International Conference on Music induced Hearing Disorders (2015 Jun.), paper 4-2.

[12] M. Kok, J. Mulder, A. J. Hill et al., "A Case Study on Sound Level Monitoring and Management at Large-Scale Music Festivals," in Proceedings of the Institute of Acoustics Conference on Reproduced Sound, vol. 41, no. 3 (Bristol, UK) (2019 Nov.).

[13] A. J. Hill, and J. Burton, "A Case Study on the Impact Live Event Sound Level Regulations Have on Sound Engineering Practice," in Proceedings of the Institute of Acoustics Conference on Reproduced Sound, vol. 42, no. 3 (2020 Nov.).

[14] A. J. Hill, J. Mulder, J. Burton, M. Kok, and M. Lawrence, "Sound Level Monitoring at Live Events, Part 1-Live Dynamic Range," J. Audio Eng. Soc., vol. 69, no. 11, pp. 782-792 (2021 Nov.). https://doi.org/10.17743/ jaes.2021.0050.

[15] J. Mulder, E. F. Beach, and R. Cowan S. McGinnity, "Management of Sound Levels in Live Music Venues," J. Audio Eng. Soc., vol. 67, no. 12, pp. 972-985 (2019 Dec.). https://doi.org/10.17743/jaes.2019.0044. 
THE AUTHORS

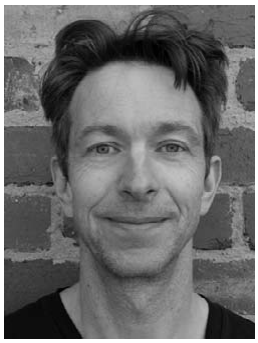

Johannes Mulder

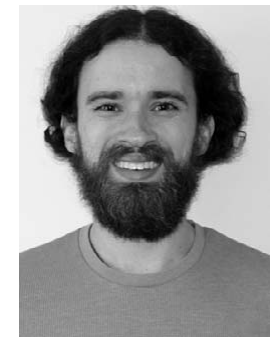

Adam J. Hill

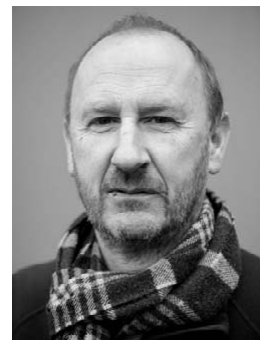

Jon Burton

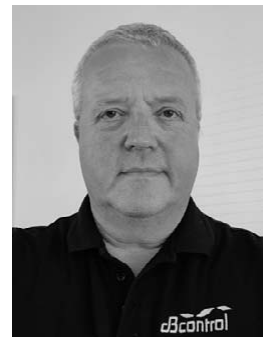

Marcel Kok

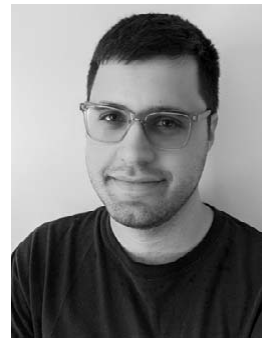

Michael Lawrence
Johannes (Jos) Mulder is a lecturer in Music Technology at the School of Music, The Australian National University. His interdisciplinary research covers different aspects of live sound, including the management and monitoring of sound levels in music venues and history of live sound practice and technology. Prior to his academic career he worked as a freelance live sound engineer for 15 years, after studying recording engineering (Tonmeister) at the Royal Conservatoire in The Hague (the Netherlands). He has a Master's in Art Management and Administration (2007, Utrecht University) and Ph.D. (2013, University of Technology, Sydney). He is a fellow of the Higher Education Academy. Jos is a member of the AES and WHO technical working group for development of the Global Standard for Safe Listening Venues.

Adam Hill is currently an Associate Professor of Electroacoustics at the University of Derby where he runs the M.Sc. Audio Engineering program. He received a Ph.D. from the University of Essex, M.Sc. in Acoustics and Music Technology from the University of Edinburgh, and B.S.E. in Electrical Engineering from Miami University. His research generally focuses on analysis, modeling, and widearea spatiotemporal control of low-frequency sound reproduction and reinforcement. Adam works seasonally as a live sound engineer for Gand Concert Sound, where he has designed and operated sound systems for over 1,000 artists. $\mathrm{He}$ is chair of the AES Technical Committee on Acoustics and Sound Reinforcement, member of the ElectroAcoustics Group Committee within the Institute of Acoustics, and member of the WHO technical working group for development of the Global Standard for Safe Listening Venues. Adam was awarded the IOA Young Persons' Award for Innovation in Acoustical Engineering in 2019. $\mathrm{He}$ is a chartered engineer and member of the AES, IOA, IEEE, and IET.

Jon Burton is a live sound engineer with many years of touring experience and currently a senior lecturer at the University of Derby. Jon has toured with acts as varied as Radiohead, Stereophonics, Lulu, and, for the last 15 years,
The Prodigy. Jon has worked at the highest level for over 30 years. Jon is also a partner in the Laundry Rooms recording studio complex in Sheffield. Jon regularly lectures at universities and colleges in the UK and abroad. Having no prior formal education in sound, Jon completed an M.Sc. in Music Technology from York University in 2017 and become a Fellow of the Higher Education Academy. Jon is a part-time writer for Sound on Sound magazine and contributes to the online education site Soul Sound.

Marcel Kok lives in the Netherlands and is CEO of $\mathrm{dB}$ Control. The main activity for $\mathrm{dB}$ Control is sound level measurements and control at live festivals, followed by consultancy and research on sound levels. Nowadays the market focus is on large outdoor dance events in the Netherlands and Belgium, and there is also dB Control Norway in Trondheim. Marcel has a degree in Electrical Engineering from the University of Twente, the Netherlands, and has completed an M.B.A. study. His work experience is in the field of acoustic consultancy. Sound engineering has been his hobby since 1982, as a freelance FOH engineer he has seen many small venues around Europe. Besides working at $\mathrm{dB}$ Control, Marcel is a Ph.D. student at Ghent University in Belgium. The topic of his research is the use of $\mathrm{dB}(\mathrm{C})$ as an indicator for the low frequency annoyance at large outdoor dance festivals. Marcel is a member of the WHO technical working group for development of the Global Standard for Safe Listening Venues.

Michael Lawrence's love affair with professional audio began at age 14 when he was left unattended in his school's auditorium. After graduating from Berklee College of Music (Boston, MA) he toured the country as a sound engineer for various artists before developing a focus on sound system measurement, analysis, and optimization. In 2019 he was adopted by Rational Acoustics, where he works feverishly on the SPL feature set for the Smaart audio analyzer in exchange for a steady diet of tacos and graham crackers. In his free time he enjoys designing and tuning sound systems, which his loved ones do not consider leisure activities, but they have agreed to disagree. 